\title{
DO CONFLICTING INTENTIONS GIVE RISE TO MULTIPLE DEMONSTRATIVE REFERENCE? REPLY TO MENA ${ }^{1}$
}

\author{
MARIO GÓMEZ-TORRENTE \\ https:/ / orcid.org/0000-0002-5957-6544 \\ Instituto de Investigaciones Filosóficas \\ Universidad Nacional Autónoma de México (UNAM) \\ Mexico City \\ Mexico \\ mariogt@unam.mx
}

\section{Article info}

CDD: 401

Received: 01.10.2020; Accepted: 17.10.2020

https://doi.org/10.1590/0100-6045.2020.V43N4.MN

\section{Keywords \\ Reference \\ Demonstratives \\ Conflicting Intentions}

\begin{abstract}
According to Ricardo Mena, a demonstrative refers to all the objects that the utterer has an intention for it to refer to, which may be more than one in cases where her referential intentions conflict. In this note I argue that Mena's proposal has several serious problems.
\end{abstract}

What in Roads to Reference I call the Simple Intention theory of demonstrative reference,

(Simple Intention) A use of a demonstrative refers to an object o iff $\mathrm{o}$ is the thing that the

\footnotetext{
${ }^{1}$ Support from the research project no. PIDPID-107667GB-I00 of the Spanish Ministry of Science and Innovation is gratefully acknowledged.
} 
utterer intends to refer to with his/her use (Gómez-Torrente (2019), 29),

is vulnerable to the problem of conflicting intentions. In many cases of uses of a demonstrative, there are two or more referential intentions behind the use that don't determine one same object, and in many of these cases, in turn, the referential intentions determine different objects, so that there is no such thing as the thing that the utterer intends to refer to with his/her use. In some of these cases it appears to be intuitively clear what the conventional reference of the use of the demonstrative is, because one of the conflicting intentions appears to override the others. To use an example from the book, also used in Ricardo Mena's (2020) commentary, imagine that you and I are watching a group of people play soccer and one of them, who wears a yellow shirt, is clearly better than the others; I also think he is my bright philosophy of language student. Pointing to the yellow image, I say That's a really good player, intending to refer to the person I'm pointing at as represented by my very perception of him, and also intending to refer to my philosophy of language student as represented by the very description "my bright philosophy of language student". Now it turns out that I am confused and the soccer player is not my philosophy of language student. The Simple Intention theory then implies that my use of "that" did not have a reference. But intuitively the conventional referent in this case is the soccer player that I see in front of me. The account of demonstrative reference in Roads to Reference implies this, as the relevant convention there postulates that in cases where one (and only one) perceptual referential intention conflicts with other non-perceptual referential intentions, the conventional referent of the use of the demonstrative in question is the object of the perceptual intention. 
In other cases of conflicting intentions, my intuition is that it is not clear, and it is probably conventionally indeterminate, that there is a referent. This is my view of Kaplan's ((1978), 239) classic example of the pictures of Spiro Agnew and Rudolf Carnap, ${ }^{2}$ also discussed in Roads to Reference and recalled by Mena, an example where the conflicting intentions can all be taken to be descriptive (though the intention to refer to the Carnap picture may as well be taken to be memorial). These cases of apparent indeterminacy constitute an important motivation for a general feature of my account of demonstrative reference in the book: the conventions for demonstrative reference and reference failure that I postulate all adopt the form of statements of sufficient conditions. This makes it possible that the resulting set of conventions giving sufficient conditions for reference and reference failure does not contemplate all situations (all the conditions) when a demonstrative might be used, and in particular that it does not contemplate all cases when a demonstrative is used with several descriptive referential intentions. If this possibility is actual, as I suspect, it implies that some uses of demonstratives are neither implied to refer by the conventions nor implied by them to fail to refer. The classic Agnew/Carnap example is in my view one of these cases.

Mena wants to defend a version of the Simple Intention theory, which could be formulated by postulating that the convention governing demonstrative reference is this:

2 Recall that in the example, Kaplan points to the wall behind him without looking at it. On that wall used to be a picture of Carnap, but now, unbeknownst to Kaplan, there is a picture of the politician Spiro Agnew. While pointing, Kaplan utters That is a picture of one of the greatest philosophers of the twentieth century. 
(Multiple Intention) A use of a demonstrative refers to an object $\mathrm{o}$ iff $\mathrm{o}$ is a thing that the utterer intends to refer to with his/her use.

The Multiple Intention convention has the effect that, at least in most cases of conflicting intentions, the relevant use of the demonstrative will have more than one thing as a conventional referent. ${ }^{3}$ In particular, in the example of the soccer player above, the theory implies that "that" refers both to the player and to my bright student; and in the Agnew/Carnap example, it implies that "that" refers to the two pictures. As we will see, Mena claims that these implications are just what we should expect.

Mena uses the following example as a motivation for the Multiple Intention theory:

Suppose you and Celeste can't find your respective books, and I know it. We are positioned in such a way that you can only see the left hand side of my body and Celeste can only see the right hand side of my body. Simultaneously I point at your book with my left hand and to Celeste's book with my right hand, while saying "That's your book". This example resembles a conflicting intentions case: I have two referential intentions each one aiming at different objects. However, it seems clear that in this case I manage to refer to both books: it's not an open question how you and Celeste should interpret my utterance.

\footnotetext{
${ }^{3}$ Mena attributes a similar view to Siegel (2002), and notes that the view is compatible with the negative conclusions in Nowak (forthcoming). I think in the case of Siegel the attribution is not quite right—-see my reply to Valente in this issue.
} 
In the example we would appear to have a use of "that" with two conventional referents, Celeste's book and mine, just as the Multiple Intention convention would have it.

Let's see how Mena says that the Multiple Intention theory handles the intuitions arising in the soccer player/bright student and Agnew/Carnap examples. He focuses almost exclusively on the Agnew/Carnap example. First he asks us to consider the intuitions we can expect in an audience who just see Kaplan pointing to the Agnew picture but don't know anything else about the case. Mena says that

it would be normal for the audience to be unclear about how to understand Kaplan's utterance of 'That's the picture of one of the greatest philosophers of the 20th century'. On Gómez-Torrente's view, this is a case of unclarity about whether there is reference. In my view it is a case of unclarity about which of the two propositions Kaplan expressed...: Kaplan referred to both the picture of Carnap and Agnew, so he expressed two propositions.

I think this is pretty clearly not right. As noted in Roads to Reference (and in several other places in the literature on demonstratives), this kind of audience will not be unclear, and will in fact think that reference has been made to the Agnew picture. At no point in the book do I appeal to the alleged unclarity intuitions of such an audience. Nor can Mena use such an inexistent unclarity as support for the claim that there was (conventional) reference to the two pictures.

Then Mena considers the intuitions of an audience fully informed about the contextual situation and about Kaplan's 
intentions. This is the kind of audience whose judgments about the case I consider relevant in the book, and the same can be said about other authors in the literature. About such an audience, Mena says:

it is fairly clear that the audience should take Kaplan to be referring to the picture of Carnap. The audience would also be in a position to dismiss Kaplan's reference to the picture of Agnew as a case of unintended reference: something they can simply ignore... in a case where the audience is fully informed, I think we would judge as incompetent someone who refrains from judging that Kaplan meant to refer to Carnap's picture and not to Agnew's.

I don't think this addresses the issue of accounting for the relevant intuitions here. There is hardly any doubt that Kaplan refers (speaker-refers, that is) to the picture of Carnap-this is just what having the corresponding referential intention amounts to-and that the informed audience will thus know this. Nor is there any doubt that Kaplan refers as well to the picture of Agnew, even if from the privileged perspective of the omniscient audience be didn't really want to, in the sense that he would not have done so if he had known that the pictures had been swapped. However, I think it's clear that these are just plain facts about how the example is constructed, and that they are irrelevant to the question at stake, which is what the use of "that" by Kaplan conventionally refers to. When we ask this to ourselves, the answer cannot simply state what the facts about Kaplan's mental life are-these are simply elements of the example as presented to an omniscient audience. It must appeal to the reflective verdict about the semantic 
facts that such an audience will give on the basis of the example. It's here that, according to me, an informed audience simply need not issue a determinate verdict, and they will not be judged incompetent if they do not. Mena does not really attempt to explain this (appearance of) semantic indeterminacy. ( $\mathrm{He}$ is obviously content with noting the, in my view irrelevant, fact that the informed audience will see that Kaplan speaker-referred to Carnap's picture but mistakenly formed an intention to refer to Agnew's. $)^{4}$

Mena's brief remarks on the intuitions about the soccer player/bright student example are, in my view, similarly misdirected. He says:

This is a case where your audience should interpret you as meaning to refer to the player you are pointing at, and, in case the audience somehow has access to your other referential intention (the one picking out your student) they should take it as mistaken, thereby ignoring your reference to the philosophy of language student.

Again, surely the informed audience will know that I speaker-referred to the guy in the yellow shirt and mistakenly formed an intention to refer to the student. But

\footnotetext{
${ }^{4}$ In this respect it's significant to recall that the previous theorists in the literature are divided among those who think that it is the picture of Agnew that is referred to and those who think that it is conventionally determined that there is reference to neither picture (and nobody seems to think that conventional reference is to the picture of Carnap). Mena does not attempt to explain this mixture of intuitions either; as noted in Roads to Reference, I take the mixture as evidence of indeterminacy.
} 
this is just a repetition of the basic facts about the example, not an explanation of the semantic intuitions that it generates. The previous literature about similar examples is highly significant here: all authors I'm aware of accept that in a case like this there is conventional reference to the guy in the yellow shirt and no conventional reference to the student. Mena does not attempt to explain these data, and in fact they would seem to go directly against his theory, for according to it, let's recall, in the example there is conventional reference to the two men. (Note that he could not attempt an explanation saying that the fact that there is reference to the two men is obscured by the circumstance that I, the speaker, mistakenly formed an intention to refer to the student. Suppose I had said, in the same scenario and with the same referential intentions, pointing to the guy in the yellow shirt, He is my bright philosophy of language student. Certainly the widespread intuition here is again that "he" conventionally refers to the soccer player, but the mistakenly formed intention is, if any, the one to refer to bim.)

Regardless of whether we could imagine some explanation for the relevant intuitions within the framework of Mena's Multiple Intention theory, there are clear problems with the theory. As Mena notes, previous theorists have taken it as obvious that uses of a singular demonstrative cannot have two semantic referents. I don't think this is just the result of some kind of unjustified tacit prejudice. Evidently "that", "he", etc. are conventionally singular terms, which is manifested in how speakers take care not to make a use of them unless they are reasonably convinced that the referential intentions accompanying the use determine a single thing. People just don't go around saying things like That is a starling! while pointing to a flock of starlings and intending to refer to all of them, though they shouldn't care much if Multiple Intention was a real 
convention. And people would say without feeling any oddness things such as $\mathrm{He}$ is John and Jim when introducing John and Jim to someone else-how could it sound odd if one had an intention to refer to John and an intention to refer to Jim, given that Multiple Intention was in place?

A usual test for whether something is part of the literal, conventional content of an utterance is to see whether that something can be felicitously reported as having been said with the utterance. If we report on Kaplan's utterance saying Kaplan said that Agnew's is a picture of one of the greatest philosophers of the twentieth century and that Carnap's is a picture of one of the greatest philosophers of the twentieth century, I think the oddness that a competent speaker will feel is clear, though there shouldn't be any oddness if Multiple Intention was a real convention of demonstrative reference. Similarly with Mario said that John (the guy in the yellow shirt) and Peter (bis philosophy of language student) are really good players. And if Rebekah (whose favorite son is Jacob) mistakes Esau for his twin and pointing to him says This is my favorite son, it will sound no less odd to report on Rebekah's utterance saying Rebekah said that Esau and Jacob are both her favorite son, even though it should sound just fine if Multiple Intention was in operation.

If the Multiple Intention theory is so implausible, what are we to make of the Celeste example that Mena used to motivate the theory? I think the answer is more or less obvious: it's a case where one same token of "that" is employed to make two uses or utterances. Though the Celeste case may have an air of atypicality for a number of other reasons, cases where a single token is employed in order to make more than one utterance are relatively common. For example, an I'll come back soon sign can be used by two different store clerks who leave the store for a while (even simultaneously) in order to make two utterances with different contents (say, to two different 
customers who may arrive while the clerks are away and who will each look for one of the two clerks). Since the Roads to Reference account is an account of the conventional reference of uses or utterances of demonstratives (not of tokens or even types in a context), it has no problem accounting for examples like the Celeste case. And in fact we have independent motivation to treat the case as one involving two utterances made with a single token, for surely such cases are feasible in situations that one would hardly think of as suggesting a multiple reference theory of the relevant indexical—like "I" in the I'll come back soon sign scenario.

\section{REFERENCES}

Gómez-Torrente, M. (2019), Roads to Reference. An Essay on Reference Fixing in Natural Language, Oxford University Press, Oxford.

Kaplan, D. (1978), "Dthat", in P. Cole (ed.), Syntax and Semantics, Volume 9: Pragmatics, Academic Press, New York, 221-43.

Mena, R. (2020), "A Bump in the Road. Comments on Roads to Reference", Manuscrito, this issue.

Nowak, E. (forthcoming), "No Context, no Content, no Problem", Mind and Language, forthcoming.

Siegel, S. (2002), "The Role of Perception in Demonstrative Reference", Philosophers' Imprint 2, no. 1, <www.philosophersimprint.org/002001>.

$(\mathrm{cc}) \mathrm{BY}$ 